Available online at http://jurnal.stmikroyal.ac.id/index.php/jurteksi

\title{
PERANCANGAN ANTARMUKA APLIKASI BERBASIS WEB MENGGUNAKAN USER CENTERED DESIGN DALAM PEMBELAJARAN KERAGAMAN BUDAYA
}

\author{
Rizky Fauziah Lubis \\ STMIK Royal, Kisaran \\ email: rizkyfauziahlbs@gmail.com
}

\begin{abstract}
An interface design for learning application is designed based on the user need. User Centered Design (UCD) purposed for help the design process match with the user need which is user usability oriented. After arranging based on that need, so the application is modelled using Unified Modelling Language (UML) to describe the systematic and how the application works from the designed application. The use of UCD can be used in designing an application for cultural diversity learning in Asahan with the $W e b$-based. The element in the information system explained graphically and expose the close relationship of each element. So by the detail design dan user need oriented, the youth attracted and willing to learn their culture by the comprehensive information system.
\end{abstract}

Keywords: User Centered Design, Unified Modelling Language, culture diversity of Asahan

\begin{abstract}
Abstrak: Sebuah perancangan antarmuka aplikasi pembelajaran disusun dan dibuat berdasarkan kebutuhan penggunanya. User Centered Design (UCD) bertujuan untuk membantu perancangan sesuai dengan kebutuhan yang berorientasi pada usability pengguna. Setelah disusun sesuai kebutuhan tersebut, maka aplikasi dimodelkan dengan menggunakan Unified Modelling Language (UML) sehingga terlihat jelas seperti apa sistematika dan operasi penggunaan dari aplikasi yang dirancang. Penggunaan UCD dapat digunakan dalam merancang suatu aplikasi pembelajaran keragaman budaya di Asahan berbasis Web. Elemen yang ada pada aplikasi ini digambarkan secara grafis dan dapat memperlihatkan hubungan yang erat antar elemennya. Sehingga melalui perancangan yang detail dan berorientasi pada kebutuhan pengguna, generasi muda tertarik dan mau mempelajari kebudayaannya sendiri melalui sistem informasi yang komprehensif.
\end{abstract}

Kata kunci: User Centered Design, Unified Modelling Language, keberagaman budaya Asahan. 
Available online at http://jurnal.stmikroyal.ac.id/index.php/jurteksi

\section{PENDAHULUAN}

Aplikasi adalah program siap pakai yang dapat digunakan untuk menjalankan perintah-perintah dari pengguna aplikasi tersebut dengan tujuan mendapatkan hasil yang lebih akurat sesuai dengan tujuan pembuatan aplikasi tersebut. Aplikasi dapat dimanfaatkan untuk keperluan kepada siswa mengingat dalam suatu proses pembelajaran seharusnya terdapat interaksi antar komponenkomponen pembelajaran. Pembelajaran keragaman budaya atau pendidikan multikultural berarti proses pengembangan seluruh potensi manusia yang menghargai pluralitas dan heterogenitasnya sebagai konsekuensi keberagaman budaya, etnis, suku dan aliran agama. Selama ini pembelajaran keragaman budaya belum mengikuti tuntutan zaman yang berorientasi pada teknologi informasi. Maka dibutuhkan teknologi untuk menjadi media pembelajaran keragaman budaya yang komprehensif. Metode UCD digunakan untuk membantu perancangan karena aspek utama dalam UCD adalah keterlibatan pengguna pada keseluruhan proses. Sehingga metode ini menjadi panduan dalam membuat aplikasi yang berorientasi pada kebutuhan pengguna.

UCD adalah proses yang interaktif dimana langkah perancangan dan evaluasi dibuat dalam permulaan proyek sampai implementasi. UCD mengikuti suatu rangkaian metodemetode dan teknikteknik dengan baik untuk analisis dan evaluasi antarmuka perangkat keras, antarmuka perangkat lunak dan antarmuka web (Ambarwati, 2009). UCD adalah perancangan antarmuka yang melibatkan pengguna, antarmuka dapat digunakan untuk menarik perhatian pengguna (Yusriel, 2008). Aspek utama dalam UCD adalah keterlibatan pengguna pada keseluruhan proses. Pengguna tidak hanya memberi komentar tentang ide perancangan, tetapi juga harus secara intensif dilibatkan dalam semua aspek, termasuk bagaimana implementasi sistem yang baru akan mempengaruhi pekerjaan mereka. Pengguna juga dilibatkan dalam pengujian awal dan evaluasi serta perancangan secara interaktif. Namun bergantung pada kompleksitas sistem yang dibangun, terdapat beberapa variasi dalam pendekatannya. Eason (1992) menggambarkan empat langkah kunci dalam pengembangan, yaitu perencanaan, perancangan, implementasi dan pengelolaan sistem (Yuliani, 2015).

\section{METODOLOGI}

\section{Analisa Sistem}

Pada penelitian ini sistem informasi berupa aplikasi pembelajaran keragaman budaya bertujuan untuk membantu perancangannya. Perancangan menggunakan metode UCD menjadi panduan untuk membuat aplikasi yang berorientasi pada kebutuhan pengguna. Aplikasi yang dirancang ditujukan untuk menarik minat siswa/i SMA kelas X-XII di Kabupaten Asahan sehingga mereka mau mempelajari kebudayaannya sendiri. Aplikasi juga dirancang untuk menampilkan informasi secara interaktif, komprehensif, serta menampilkan doku-mentasi berupa foto dan video.

Metode UCD merupakan metode yang digunakan dalam perancangan antarmuka aplikasi pembelajaran keragaman budaya di Asahan.

\section{Alur Proses Kerja \\ Diagram di atas menjelaskan bahwa proses perancangan dimulai dengan melakukan observasi dan analisa yang direalisasikan dengan menyebarkan kuesioner kebutuhan pengguna. Selain itu observasi juga dilakukan dengan mengumpulkan data dari Disporabudpar Kabupaten Asahan sebagai lembaga pemerintah daerah resmi yang menaungi keberagaman budaya di Asahan. Ber- dasarkan data yang terkumpul kemudian}


Available online at http://jurnal.stmikroyal.ac.id/index.php/jurteksi

diimplementasikan dengan menggunakan metode UCD dan hasilnya dimodelkan dengan menggunakan UML. Setelah proses analisa selesai maka pembuatan aplikasi dimulai. Tahap akhir ditandai dengan dilakukannya pengukuran usability dari aplikasi dengan menyebarkan kuesioner kepada pengguna.

\section{Analisia Masalah}

Pada pengumpulan data ditemukan bahwa jenis budaya belum diketahui dengan sempurna oleh para siswa/i SMA di kabupaten Asahan karena tidak adanya kurikulum maupun muatan lokal (mulok) di sekolah. Penggiat budaya di kalangan sekolah hanyalah guru kesenian saja, sedangkan di masyarakat hanya berasal dari anggota lembaga adat yaitu FORKALA (Forum Komunikasi Antar Lembaga Adat). Maka dari itu dibutuhkan sebuah aplikasi sistem informasi yang merangkum segala jenis dan produk budaya sebagai media komprehensif untuk pembe-lajaran budaya bagi siswa/i SMA.

UCD pada perancangan ini digunakan untuk membantu meng-analisa kebutuhan pengguna sehingga sesuai dengan target pengguna. Melalui analisa UCD akan ditentukan bagaimana perancangan yang sesuai untuk membuat aplikasi pembelajaran keragaman budaya bagi siswa/i SMA di Kabupaten Asahan. Aplikasi yang dibutuhkan adalah aplikasi interaktif dan personalized, artinya menarik setiap pribadi siswa yang berusia 15-18 tahun untuk mempelajari budaya karena memiliki keterkaitan dengan kepribadiannya, kesehariannya, dan lingkungan sekitarnya. UML diguna-kan untuk memodelkan proses dari analisa yang dihasilkan oleh proses UCD sehingga terlihat jelas struktur Web dari aplikasi yang dibangun. Pemodelan proses ini berguna untuk memudahkan developer atau programer untuk mengembangkan Web.

\section{Analisa Konsep UCD}

Setelah mendapatkan seluruh data yang berhasil dikumpulkan maka proses pengolahan akan dilanjutkan pada tahap analisa. Tahap ini bertujuan untuk menentukan user, proses, data, dan teknologi yang digunakan. Berikut penjelasan secara rinci masing-masing item.

\section{User dan Data}

Analisa user dibagi menjadi dua yaitu kebutuhan pengguna dan karakteristik pengguna. Analisa kebutuhan pengguna ditentukan dengan menyebarkan kuesioner kepada target pengguna (siswa/i SMA kelas X-XII) yang didalamnya merangkup pertanyaan mengenai respon mereka terhadap perancangan aplikasi berbasis Web yang akan dibangun.

Analisa karakteristik pengguna yang ditentukan berdasarkan target pengguna yaitu siswa/i SMA di kabupaten Asahan dilakukan untuk melihat seperti apa perancangan yang tepat. Tahap ini bertujuan untuk melakukan sinkronisasi kondisi para siswa/i yang pada umumnya telah mampu menggunakan internet dan menggunakan Web browser untuk mengakses informasi terhadap aplikasi yang dirancang berbasis Web.

Data yang dipakai dalam perancangan ini adalah data berbentuk file Microsoft Excel dari Disporabudpar Kabupaten Asahan.

\section{Teknologi yang Digunakan}

Teknologi pada perancangan ini memusatkan pada maksimalisasi penggunaan Web. Alasan pemilihannya adalah melihat bahwa siswa/i SMA di Kabupaten Asahan yang cenderung membuka internet dengan menggunakan perangkat PC. Keadaan koneksi internet di setiap daerah di Kabupaten Asahan beragam dengan tingkat koneksi sedang hingga buruk. Maka perancangan difokuskan pada penggunaan Web yang berpotensi untuk menarik minat penggunanya. Selain 
Available online at http://jurnal.stmikroyal.ac.id/index.php/jurteksi

itu, keberadaan warung internet (warnet) dan antusias menggunakan laptop dengan koneksi WiFi di beberapa titik tertentu. Sehingga perancangan menggunakan Web diprediksi memudahkan penggunanya dan akan mampu memenuhi kebutuhan penggunanya.

\section{HASIL DAN PEMBAHASAN}

\section{Implementasi}

Implementasi dari penerapan User Centered Design (UCD) dalam perancangan antarmuka aplikasi berbasis web untuk pembelajaran keragaman budaya di kabupeten Asahan dengan menggunakan beberapa software pendukung yang dibutuhkan. Software pendukung yang digunakan dalam penelitian ini yaitu Adobe Dreamwaver CS3 sebagai software editor perancangan aplikasi, bahasa pemrograman PHP, dan pengolahan database menggunakan MySQL.

\section{Tampilan Halaman Login}

Tampilan halaman login sistem merupakan sebuah tampilan awal ketika mengunjungi sistem aplikasi. Pada tampilan halaman login sistem terdapat sebuah form yang berguna untuk menginputkan username dan password untuk dapat masuk ke dalam sistem yang telah disediakan.

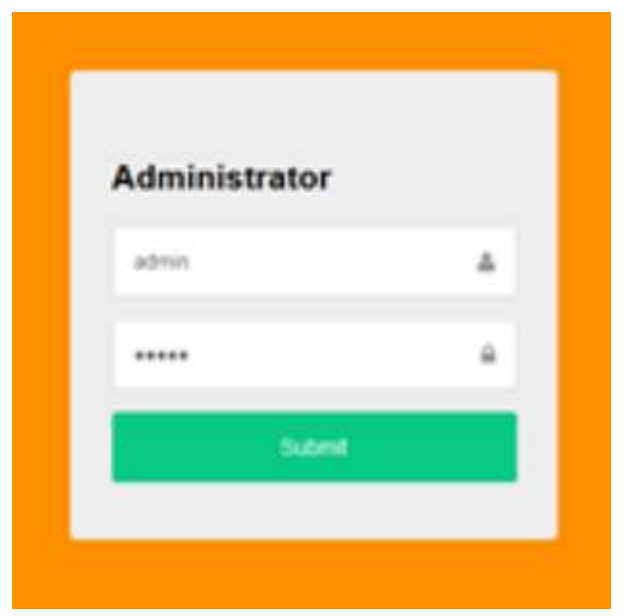

Gambar 2. Halaman Login

\section{Tampilan Halaman Utama Admin}

Tampilan halaman utama sistem ini merupakan sebuah halaman yang akan tampil setelah berhasil melakukan login yang selanjutnya digunakan untuk mengelola master dan budaya asahan ke dalam sistem.

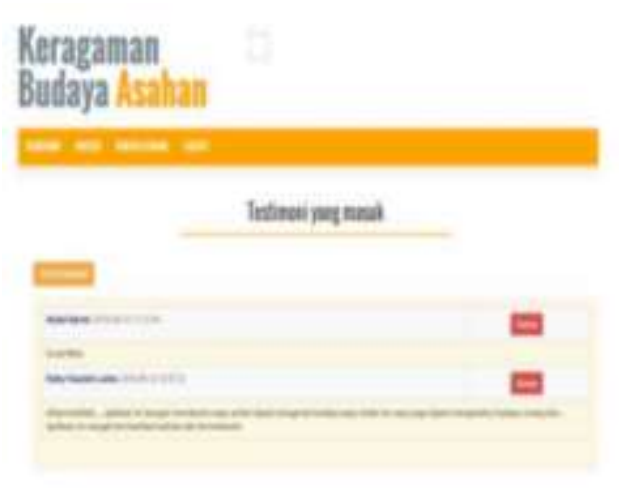

Gambar 3. Halaman Utama Admin

Tampilan Hasil Input Master Bagian Kecamatan

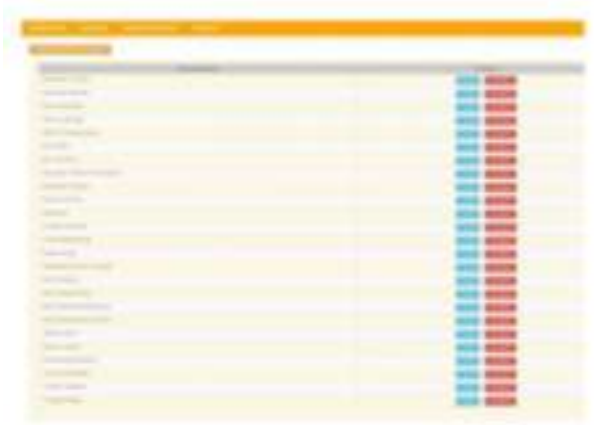

Gambar 4. Hasil Input Master Bagian Kecamatan

Tampilan Hasil Input Master Bagian Etnis

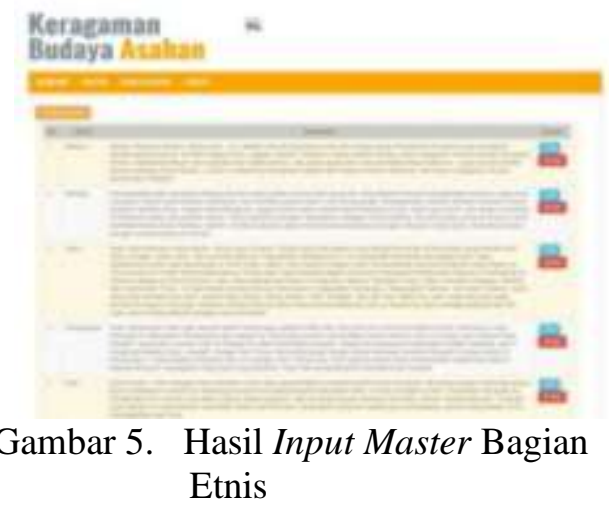


Available online at http://jurnal.stmikroyal.ac.id/index.php/jurteksi

\section{Tampilan Hasil Input Master Bagian Benda Cagar Budaya}

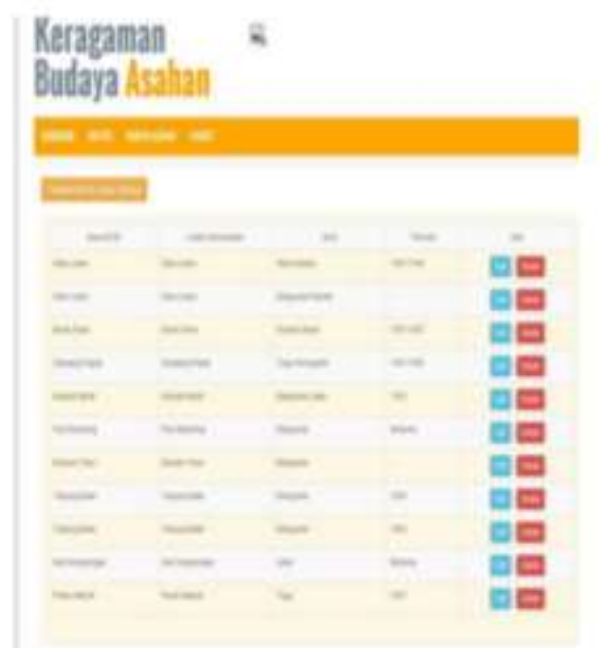

Gambar 6. Hasil Input Master Bagian Benda Cagar Budaya

Tampilan Hasil Input Budaya Asahan Bagian Komunitas Adat
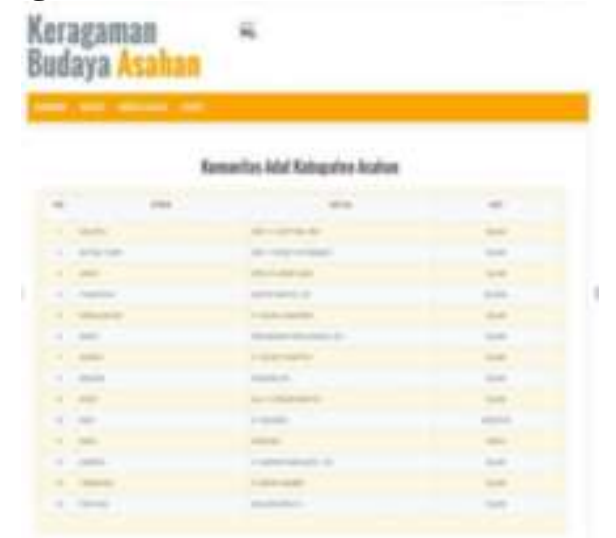

Gambar 7. Hasil Input Budaya Asahan Bagian Komunitas Adat

Tampilan Hasil Input Budaya Asahan bagian Lembaga Adat

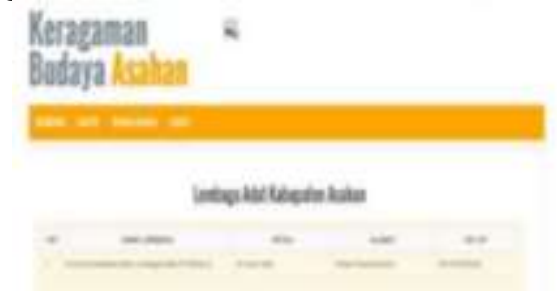

Gambar 8. Hasil Input Budaya Asahan Bagian Lembaga Adat
Tampilan Hasil Input Budaya Asahan bagian Sanggar Seni

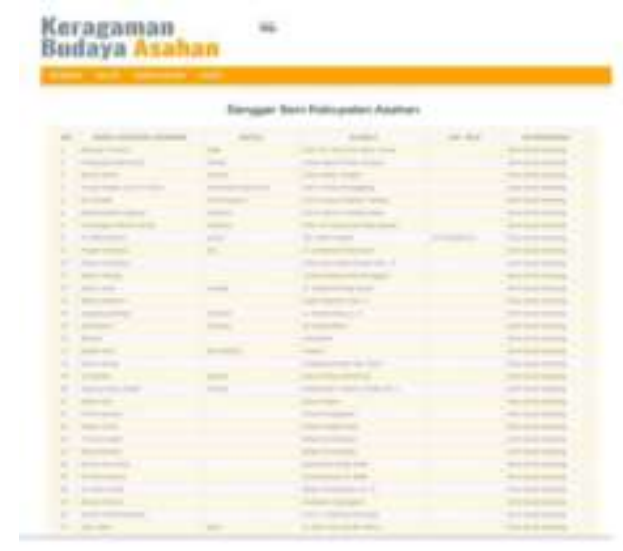

Gambar 9. Hasil Input Budaya Asahan Bagian Sanggar Seni

\section{Tampilan Halaman Utama Pengun- jung}

Tampilan halaman utama sistem ini merupakan sebuah halaman yang akan digunakan bagi pengunjung untuk mendapatkan informasi tentang keragaman budaya di Asahan.

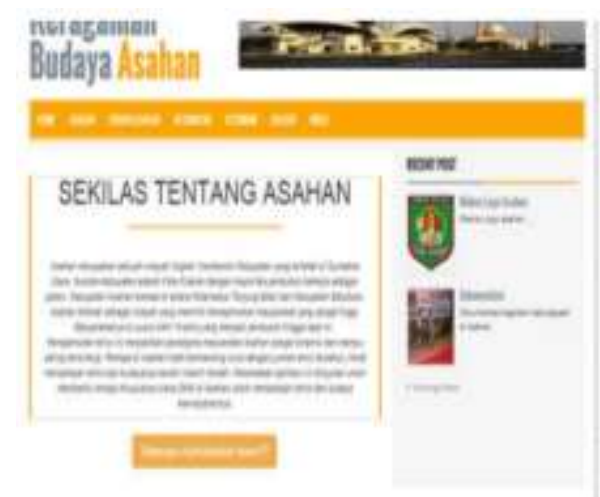

Gambar 10. Halaman Utama Pengunjung

\section{Pengujian}

Pengujian dilakukan dengan cara mengukur atau mencapai usability yang baik seperti aman untuk digunakan, memiliki manfaat yang baik, mudah untuk digunakan serta memuaskan dan menarik minat para siswa SMA.

Pengujian dilakukan dengan cara memberikan kuesioner kepada beberapa siswa yang memuat tentang beberapa 
Available online at http://jurnal.stmikroyal.ac.id/index.php/jurteksi

pertanyaan. Pertanyaan tersebut mengenai usability penggunaan aplikasi pembelajaran keragaman budaya di Asahan. Siswa akan menjawab pertanyaan berupa tanggapan siswa terhadap penggunaan aplikasi pembelajaran keragaman budaya di Asahan dan memperhatikan setiap fungsi serta manfaat belajar menggunakan aplikasi yang telah dibangun.

Setelah mendapatkan hasil tanggapan mahasiswa dapat disimpul-kan bahwa aplikasi pembelajaran keragaman budaya di Asahan sudah dapat digunakan dengan baik dengan penyajian materi yang mudah dipahami serta mudah dipelajari. Adanya fitur video dan galeri membantu siswa untuk mendapatkan visualisasi tentang berbagai item mengenai kebudayaan itu sendiri. Serta adanya fitur testimoni dapat menjadi wadah siswa menyalurkan saran dan kritiknya terhadap aplikasi keragaman budaya di Asahan.

\section{SIMPULAN}

Berdasarkan hasil analisa dan pembahasan, maka dapat ditarik simpulan sebagai berikut:

1. Perancangan antarmuka aplikasi pembelajaran keragaman budaya di Asahan

\section{DAFTAR PUSTAKA}

Murtiwiyati \& Lauren. (2013) Rancang Bangun Aplikasi Pembelajaran Budaya Indonesia untuk Anak Sekolah Dasar Berbasis Android. Jurnal Ilmiah Komputasi. 12(2).

Nandari \& Sukadi. (2014). Pembuatan Website Portal Berita Desa Jetis Lor. Indonesian Journal on Networking and Security. 3(3).

Novita \& Sari. (2015) Sistem Informasi Penjualan Pupuk Berbasis ECommerce. Jurnal TEKNOIF. merupakan suatu aplikasi yang dirancang dengan menggunakan tampilan Web untuk membantu para pengguna memahami seluruh unsur keragaman budaya yang ada di Asahan.

2. Pada penelitian ini konsep User Centered Design mampu merancang dan membangun suatu aplikasi berbasis Web yang sesuai dengan kebutuhan siswa/i SMA.

3. Pemodelan UML membantu dalam memodelkan konsep perancangan antarmuka aplikasi pembelajaran keragaman budaya di Asahan yang dibangun, sehingga diketahui struktur dan sistem dari aplikasi yang dibangun.

4. Perancangan antarmuka aplikasi pembelajaran keragaman budaya di Asahan yang dibangun mampu mempermudah siswa/i SMA dalam mempelajari keragaman budaya dan mendapatkan informasi komprehensif baik secara narasi, foto, maupun video. 5. Pengukuran usability dari program yang dirancang menunjukkan bahwa perancangan antarmuka aplikasi pembelajaran keragaman budaya di Asahan mampu memenuhi kebutuhan pengguna dan sesuai dengan karakteristik pengguna.
$3(2)$.

Rai \& Dhir. (2014) Impact of Different Methodologies in Software Development Process. International Journal of Computer Science and Information Technologies (IJCSIT). 5(2)

Yuliani \& Prasojo. (2015). Rancang Bangun Sistem Informasi Obyek Wisata Berbasis Web Menggunakan Metode User Centered Design (UCD). 7(2) 